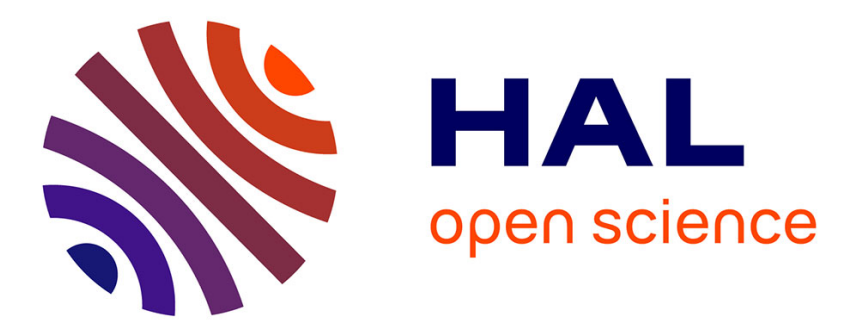

\title{
Correlation of in-flight displacement damage on the osl sensor with space environment on-board jason-2 spacecraft
}

\author{
S. Bourdarie, D. Falguere, C. Inguimbert, C. Deneau, J.-R. Vaillé, E.
} Lorfèvre, R. Ecoffet

\section{To cite this version:}

S. Bourdarie, D. Falguere, C. Inguimbert, C. Deneau, J.-R. Vaillé, et al.. Correlation of in-flight displacement damage on the osl sensor with space environment on-board jason-2 spacecraft. Radiation Effects on Components and Systems 2013 (RADECS 2013), Sep 2013, OXFORD, United Kingdom. hal-01057371

\section{HAL Id: hal-01057371 \\ https://hal-onera.archives-ouvertes.fr/hal-01057371}

Submitted on 22 Aug 2014

HAL is a multi-disciplinary open access archive for the deposit and dissemination of scientific research documents, whether they are published or not. The documents may come from teaching and research institutions in France or abroad, or from public or private research centers.
L'archive ouverte pluridisciplinaire HAL, est destinée au dépôt et à la diffusion de documents scientifiques de niveau recherche, publiés ou non, émanant des établissements d'enseignement et de recherche français ou étrangers, des laboratoires publics ou privés. 


\title{
Correlation of in-flight displacement damage on the OSL sensor with space environment on-board Jason- 2 spacecraft
}

\author{
S. Bourdarie, D. Falguere, C. Inguimbert, C. Deneau, J.-R. Vaillé, E. Lorfèvre, R. Ecoffet
}

\begin{abstract}
Displacement damage doses measured by the ICARENG/OSL sensor on board the French JASON2 spacecraft from CNES, the French space agency, are compared to predictions performed with (1) proton measurements performed with the spectrometers on board the same spacecraft/instrument and (2) protons spectrum predicted by the legacy AP8min model and the future AP9 perturbed model.
\end{abstract}

\section{INTRODUCTION}

Because of their harmful effects on human bodies (energetic deposits in human tissues or organs) and spacecrafts electronics (discharges, SEEs ...), the Earth's radiation belts have been intensively studied since their discovery in 1958. Spacecraft engineers need a reliable and statistical description of the belts to design space missions. The current standard models, AE8 [1] and AP8 [2], were developed by NASA at the end of the 1970s and beginning of the 1980s. Different studies have put forward their shortcomings ([3] and [4]): inadequate resolution at low altitude, no variability on time-scales less than a solar cycle, etc. To overcome these limitations a recent effort in the US has allowed to release the AE9 and AP9 specification models [4]. The major innovation with these new models is their ability to provide quantification of uncertainties.

To better validate and control uncertainties on space environment and effect determination, a first generation of the ICARE ("Influence sur les Composants Avancés des Radiations de l'Espace") radiation detector was embarked in 2000 on board the Argentinean satellite SAC-C [5]. This instrument was designed in order to (1) measure electron and proton fluxes at the spacecraft location and effects of ionizing particles on various electronic devices. The effects investigated are Total Ionizing Dose (TID), Single Event Effects (SEE) and Displacement Damage Dose (DDD). A new design was implemented to increase the capabilities of

This work was supported by grant $n^{\circ}$ R-S12/MT-0003-107 which is part of CNES R\&T program.

S. Bourdarie, D. Falguere and C. Inguimbert with the Office National d'Etudes et de Recherches Aérospatiales/Département Environnement Spatial, 31400 Toulouse France (telephone; +33-562-2756, fax : +33-5622569, e-mail: Sebastien.Bourdarie@onera.fr).

C. Deneau is with Université Montpellier 2-IES, 34095 Montpellier cedex 5, France (e-mail: christelle.deneau@ies.univmontp2.fr)

J.R. Vaillé is with the Université Montpellier 2-IES, 34095 Montpellier cedex 5, France, and also with the Université de Nimes, 30021 Nimes, France

E. Lorfèvre and R. Ecoffet are with CNES, 18 av. E. Belin 31401 Toulouse, France
ICARE (called here ICARE-NG, NG for Next Generation). This new radiation monitor allows to measure proton flux in the range $27.5-292 \mathrm{MeV}$ and electron flux in the range 1.63.6 MeV thanks to 3 telescopes [6]. DDD is evaluated using the degradation of a Light Emitting Diode (LED) embedded in an OSL sensor ([7] to [12]). The first ICARE-NG unit is flying on-board the French satellite JASON-2.

The aim of this paper is first to cross validate DDD monitoring deduced from the variation of the current through the stimulation LED of the OSL sensor and deduced from the proton measurements with the 3 spectrometers. In section II in flight data are presented and in section III the approach to compute DDD is detailed. Taking the advantage of having access to (1) the full spacecraft geometry and (2) the environment measurements and (3) the effect (here limited to the DDD) done on the same body, it is then possible to evaluate accurately specification models uncertainties such as AP8 and the newly AP9 models. This is done in section IV.

\section{IN FLIGHT DATA}

The, French, JASON-2 spacecraft is flying on a Low Earth Orbit (altitude: $1336 \mathrm{~km}$, inclination: $66^{\circ}$ ) and was designed for a five years lifetime. One of the payloads is the ICARE-NG instrument which was built in the frame of the CARMEN ("CARactérisation et Modélisation de l'ENvironnement") project. It was placed inside the satellite, behind the honeycomb wall (Fig. 1).

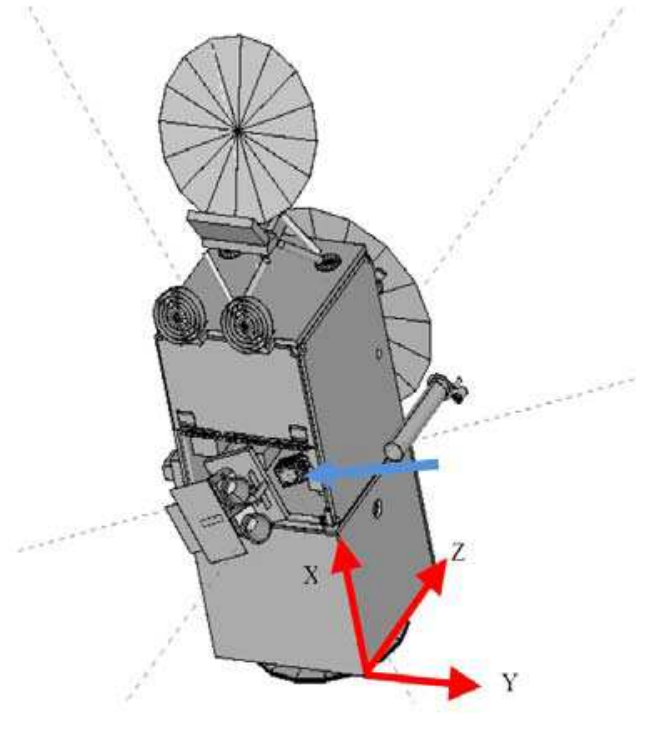


Fig. 1: Schematic view of JASON-2 spacecraft with the location of the ICARE-NG instrument indicated by the blue arrow (note that part of the honeycomb has been removed in this view to see the instrument)

The ICARE-NG instrument on-board JASON-2 began its operation in June 22, 2008 and is still running successfully. Note that the data covers the current solar cycle (Fig. 2) and in particular the last solar minimum when the solar activity was extremely low for an un-preceding long time since beginning of space age.

$$
\text { IPSAT-V5.4b-SVN:599 }
$$

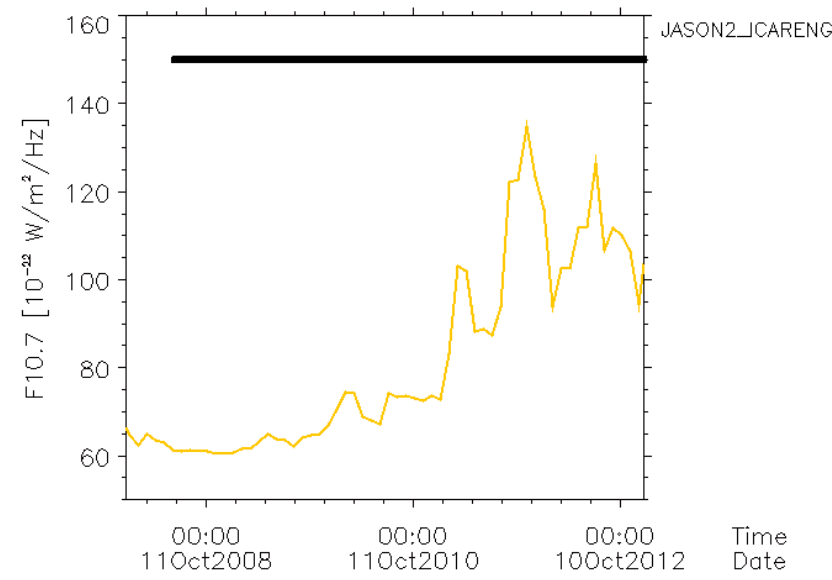

Fig. 2: Coverage of ICARE-NG measurements versus time. The yellow curve indicates the solar activity via F10.7 index.

\section{A. Total Displacement Damage Dose (DDD) measurements}

DDD is evaluated using the degradation of a Light Emitting Diode (LED) embedded in an OSL sensor. The LED was fully calibrated before launch, in term of sensitivity to temperature and current through the LED versus DDD. All details about the instrument and data analysis can be found in [7]-[11].

The time resolution for the DDD is 6 hours and data from June 22, 2008 to November 27, 2012 are considered. Careful attention was taken to correct the temperature effect on the current through the LED (the temperature of the ICARE-NG is part of the housekeeping data of the instrument, see [11] for more details). Also, the conversion from LED current to DDD is done according to ground calibration [12].

To calculate the error on the OSL measurements, we must consider the quantization noise of the LED current $\left(2.03 \times 10^{-2} \mathrm{~mA}\right)$ and the temperature $\left(3.21 \times 10^{-2}{ }^{\circ} \mathrm{C}\right)$ measurements used in the temperature effect correction and the calibration. The absolute error is evaluated to $2 \times 10^{5}$ $\mathrm{MeV} \cdot \mathrm{g}^{-1}$.

\section{B. Proton flux measurements}

The ICARE-NG instrument is also composed of a radiation monitor. Three telescopes (A, B and C) allow to measure electrons and protons in the energy range 1.6-3.6 $\mathrm{MeV}$ and 27.5-292 $\mathrm{MeV}$ respectively [6]. The time resolution is $16 \mathrm{~s}$. Since the beginning of mission the time coverage is extremely good and except few days it is closed to $100 \%$ (Fig. 3) leading to an overall coverage from June 22, 2008 to end of 2012 to $98.18 \%$.

The radiation monitor was fully calibrated at ground before flight and response functions were deduced from Monte-Carlo runs accounting for the full spacecraft geometry around each solid state detectors (see [6] for more details). IPSAT-V5.4b-SVN:599

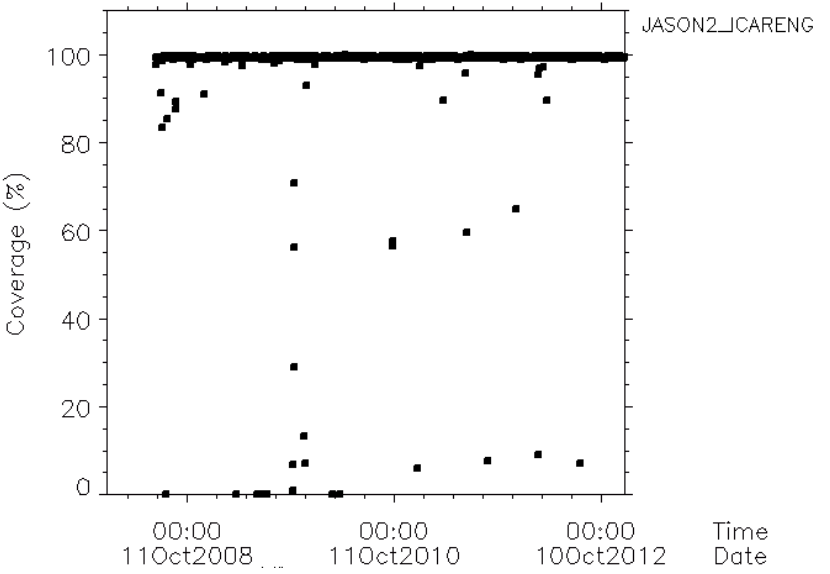

Fig. 3: Percentage of ICARE-NG measurements available per day on-board JASON-2 from beginning of mission to end of 2012.

In the current study, we will focus on proton measurements as displacement damage at low altitude is expected to be only due to protons. 17 differential channels are available (27.5, 86., 89., 91., 93., 95., 98., 104., 105., 112., 114., 120., 126., 132., 139., 142. and 155. MeV) and 21 integral channels $(>63 .,>64 .,>69 .,>76 .,>80 .,>83 .,>87$., $>93 .,>94 .,>97 .,>104 .,>108 .,>113 .,>115 .,>119 .,>127$., $>138$., $>163 .,>186 .,>222$. and $>292$. MeV). To evaluate accurate displacement damage dose from those measurements, it is necessary to compute a differential spectrum over the energy range being measured.

To do so, proton fluxes, differential and integral ones, are first daily averaged along the spacecraft orbit. Then to combine daily differential and integral spectrum into a unique differential one, it is necessary to derive differential fluxes from the integral spectrum. A simple differentiation of integral flux is not the right approach because a small uncertainty on integral flux measurements leads to large errors in differential fluxes. Moreover because the spectral definition is very high in some cases it could lead to negative differential flux. To overcome this source of uncertainty, a good alternative is to approximate the integral spectrum (in $\log -\log$ ) by a polynomial of degree 4 . It is then trivial to compute a differential spectrum.

An example is given for the day of June $23^{\text {rd }} 2008$ on Fig.4. Note that a polynomial of degree 4 reproduces with high fidelity the measures. Differential flux, thus obtained, are very close to those measured when both spectrum overlaps (Fig.5). 


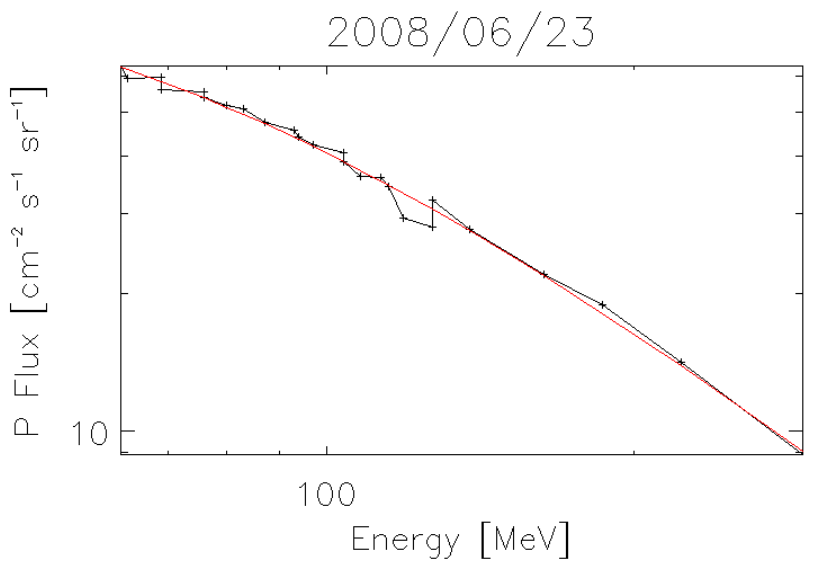

Fig. 4: Integrated flux spectrum in black and approximation by a polynomial of degree 4 in log-log in red.

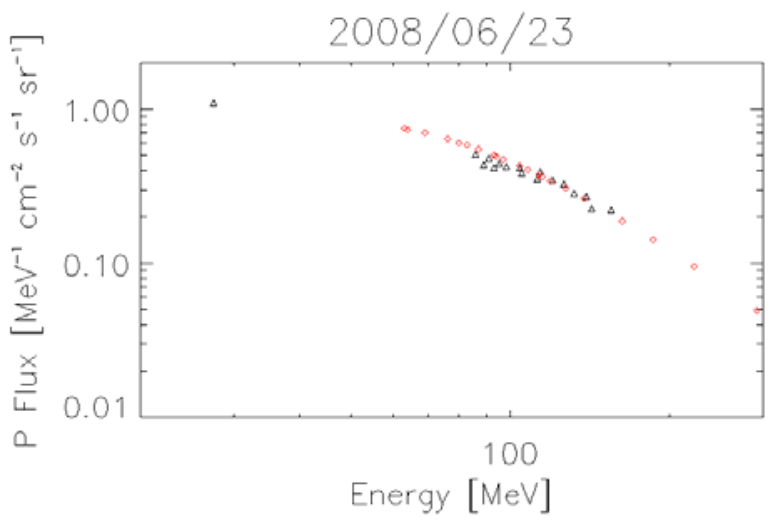

Fig. 5: Differential spectrum with ICARE-NG measurements in black and differential spectrum deduced from integral measurements in red.

To make sure this approximation is valid over the entire period under study, the "chi-square" of the fit (in $\log ($ flux $)-\log ($ energy)) is computed (Fig. 6). It may be noted that this value remains low and is on the order of $4.10^{-4}$. Nevertheless, on March 16, 2012 the value of chi-square is double. A visual inspection of this spectrum, has allowed validating this spectrum as well.

Following this strategy, a differential spectrum from $22.5 \mathrm{MeV}$ to 292 . MeV could be computed with 38 energy channels. Because there is no measure available from 22.5 $\mathrm{MeV}$ to 63 . $\mathrm{MeV}$ a simple interpolation in log-log was applied to each daily spectrum to include differential flux values at the following energies: 30., 35., 40., 45., 50., 60. MeV. On Fig.5, it can be seen that the differential flux at 63 $\mathrm{MeV}$ is on the order of $0.8 \mathrm{MeV}^{-1} \mathrm{~cm}^{-2} \mathrm{~s}^{-1} \mathrm{sr}^{-1}$ and at 27.5 $\mathrm{MeV}$ it is on the order of $1 \mathrm{MeV}^{-1} \mathrm{~cm}^{-2} \mathrm{~s}^{-1} \mathrm{sr}^{-1}$. The very small difference between these two differential fluxes is also true for every day computed spectrum. So a negligible uncertainty is expected due to the interpolations between 27.5 and 63 . $\mathrm{MeV}$.

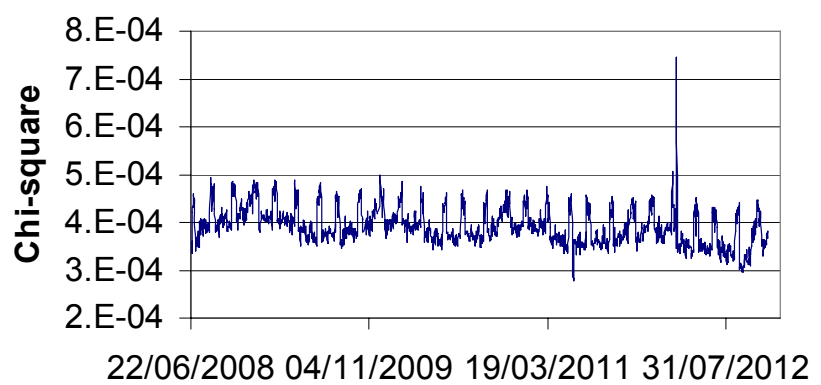

Fig. 6: Daily chi-square of integral spectrum fit versus time.

As evaluated in [6], the overall uncertainties of the differential fluxes should not exceed $20 \%$.

\section{OSL RESPONSE FUNCTION}

To calculate an accurate DDD of the LED part of the OSL sensor, the 3D shielding around the OSL must be well known. The statistical distribution of shielding thicknesses seen by the OSL sensor was calculated by a sector analysis carried out by the TRAD company using the FasTRAD software [13]-[15] (Fig. 7). It consists in partitioning the solid angle viewed from the LED in 80000 sectors of equal value (200 steps in polar angles and 400 steps in azimuthal angles).

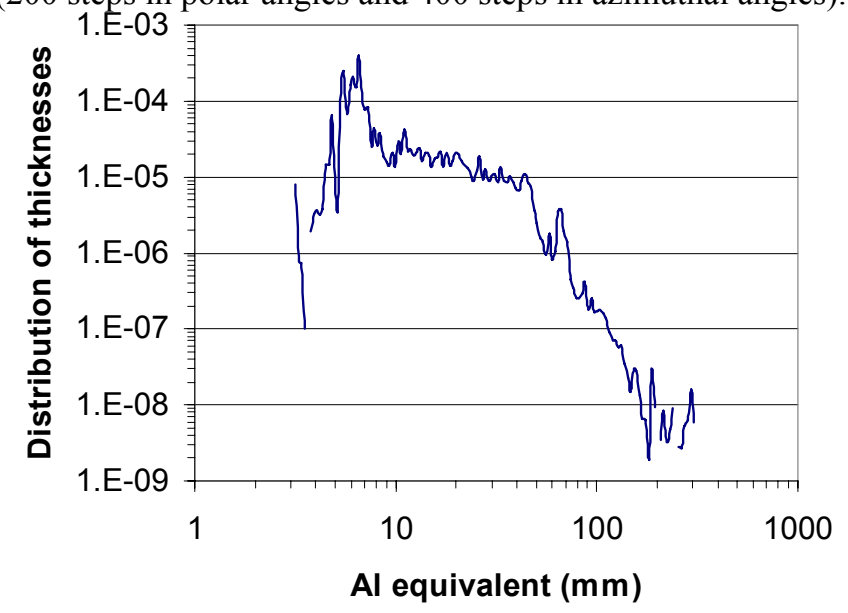

Fig. 7: Distribution of Al equivalent shielding thicknesses (in $\mathrm{mm}$ ) as viewed by the OSL sensor.

Another way to represent the shielding around the OSL sensor consists of two "fish eye" views (Fig. 8), one forward $(2 \pi$ steradians) and the other backward $(2 \pi$ other steradians). 

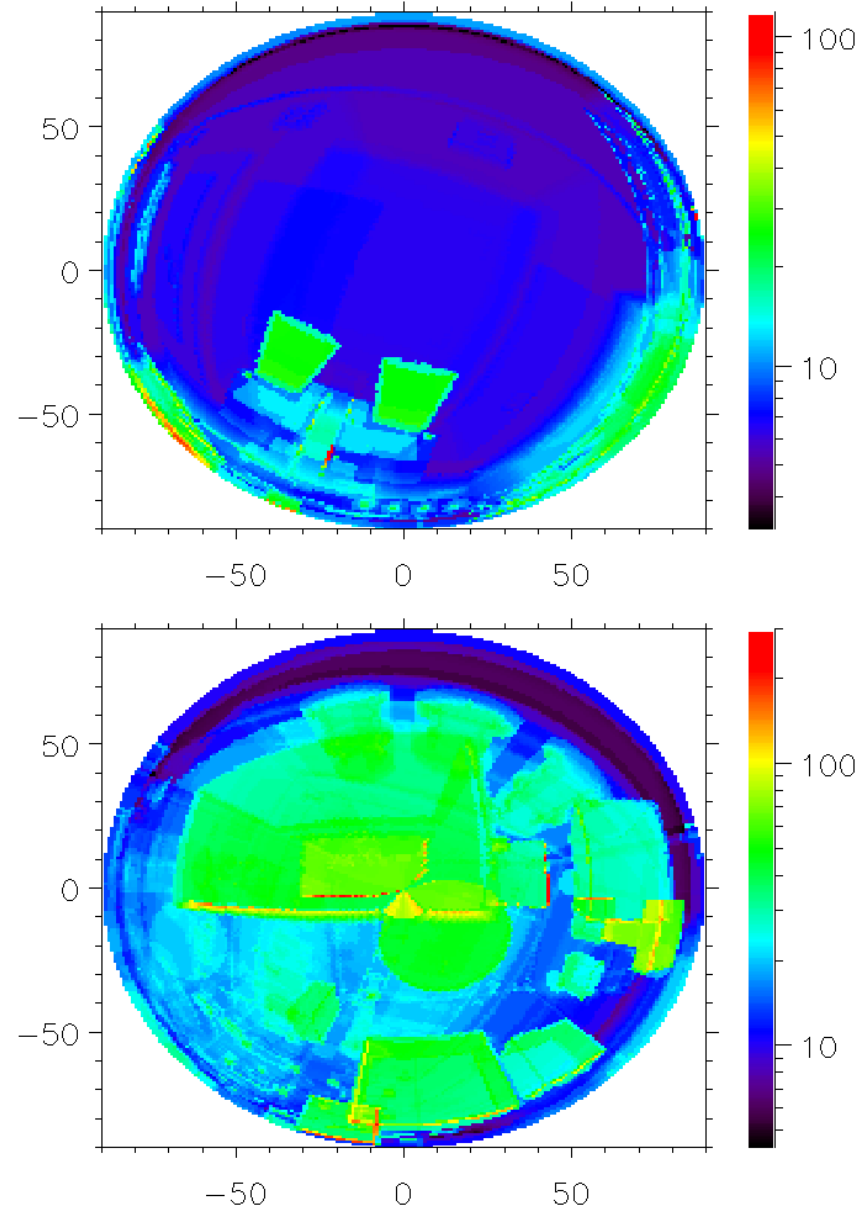

Fig. 8: "Fish eye" views of the shielding around the OSL sensor bottom is forward ( $2 \pi$ steradians) and top is backward ( $2 \pi$ other steradians). Color scale is in $\mathrm{mm}$.

For the 3D shielding of the OSL sensor, given by the normalized distribution of shielding thicknesses, dS / dh, the DDD rate can be easily calculated. The average $\frac{\partial D D D(E)}{\partial E}$ $\left(\mathrm{g}^{-1} \mathrm{~s}^{-1}\right)$ for a given incident energy $\mathrm{E}$ will be given by:

$$
\left\langle\frac{\partial D D D(E)}{\partial E}\right\rangle=\int \frac{\partial D D D(E, h)}{\partial E} \cdot \frac{d S}{d h}(h) \cdot d h
$$

where $\mathrm{h}$ is the $\mathrm{Al}$ equivalent thickness, $\mathrm{dS} / \mathrm{dh}$ the normalized distribution of $\mathrm{Al}$ equivalent thicknesses. $\frac{\partial D D D(E, h)}{\partial E}$ is for a given shielding thickness $\mathrm{h}$, the damage dose rate per unit of incident energy. It is expressed in $\left(\mathrm{MeV} \cdot \mathrm{g}^{-1} \mathrm{~s}^{-1}\right) \mathrm{xMeV}^{-}$ $\left.{ }^{1}\right)$. It corresponds to the contribution to displacement damage dose at energy $\mathrm{E}$ of shielding directions whose thickness is $\mathrm{h}$, for an isotropic differential proton flux is given by:

$$
\frac{\partial D D D(E, h)}{\partial E}=\frac{1}{2} \int_{0}^{\pi / 2} \frac{d \Phi}{d E}(E) \cdot \operatorname{NIEL}\left(r(E)-\frac{h}{\cos (\theta)}\right) \cdot \sin (\theta) \cdot d \theta
$$

where $\frac{d \Phi}{d E}$ is the differential proton flux (in $\mathrm{MeV}^{-1} \mathrm{~cm}^{-2} \mathrm{~s}^{-1}$ ) at energy $E, r(E)$ is the proton with energy $E$ range, and $\theta$ is the proton incidence angle. Note that in this calculation the straggling is neglected.

Then, the response function $\mathrm{RF}(\mathrm{E})$ of the OSL sensor (Fig. 9) is calculated from (1) as a function of proton incident energy, $\mathrm{E}(\mathrm{MeV})$, assuming $\frac{d \Phi}{d E}=1\left(\mathrm{MeV}^{-1} \mathrm{~cm}^{-2} \mathrm{~s}^{-1}\right)$ in (2).

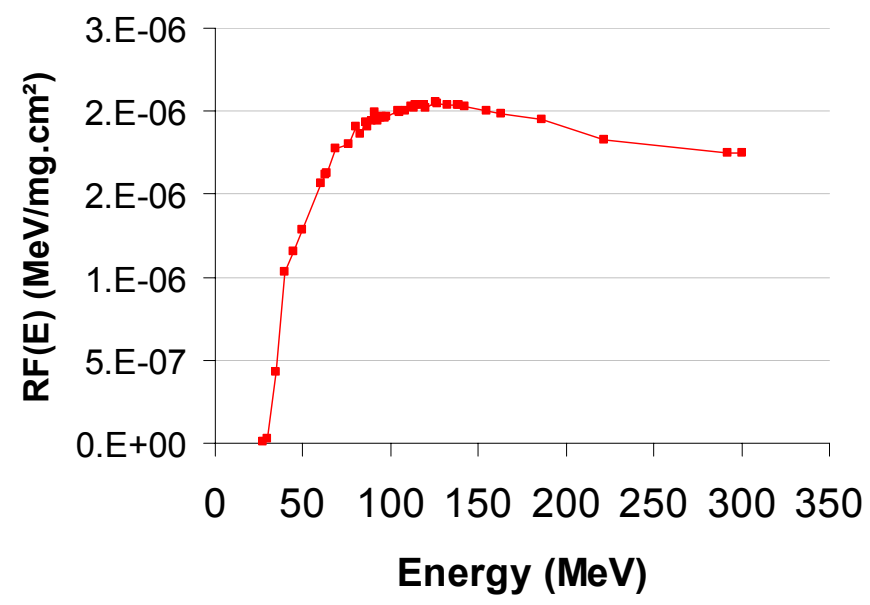

Fig. 9: Response function of damage factor of the OSL sensor considering isotropic proton incidence versus proton energy.

\section{DISPLACEMENT DAMAGES PREDICTION OF THE OSL}

\section{A. Calculation using the proton fluxes from the ICARE-NG spectrometers}

The daily DDD, DDD(day), of the OSL sensor is computed according to:

$$
D D D(\text { day })=\int_{0}^{86400} \int_{E=27.5 \mathrm{MeV}}^{E=292 \mathrm{MeV}} \frac{d \Phi}{d E}(E, t) \cdot R F(E) \cdot d E \cdot d t \text { (3) }
$$

Note that the bounds of the energy integral are restricted to 27.5 to $292 \mathrm{MeV}$ instead of 0 to infinity. This is due to the energy coverage of the ICARE-NG instrument onboard JASON-2 spacecraft. On one hand, the lower bound of $27.5 \mathrm{MeV}$ does not impact the result of the integral because the response function of the OSL sensor is equal to 0 for incident protons with energies less than $40 \mathrm{MeV}$ and on the other hand it is expected that proton fluxes at energies greater than $292 \mathrm{MeV}$ are very low compared lower energy ones such that their contribution to the integral is negligible.

Taking as input the daily proton fluxes from the ICARE-NG telescopes (see II.B.), the daily DDD obtained from (3) is plotted versus time on. The results indicate that the daily DDD fluctuates around $1.610^{6} \mathrm{MeV} / \mathrm{g} / \mathrm{day}$, this being attributed to orbital effects (how JASON-2 is crossing the South Atlantic Anomaly from one day to the next). Next the solar cycle modulation can be seen, though it is a very week effect at this altitude: the daily DDD increases a little bit from 2008 to 2009 and then decreases very slowly after end of 2010. Note that this variation is less than $10 \%$ along the time period under study. Finally, the influence of the March 2012 solar flare protons is clearly visible. It has only increased the daily DDD by a factor varying from 1 . to 2 . from March 07, 2012 to March 09, 2012 i.e. for 3 days. On 
Fig.10, the solar flare protons measured by GOES spacecraft series in the range $39 .-80 \mathrm{MeV}$ is given to pinpoint individual flares that can affect the DDD. According to DDD prediction from the ICARE-NG spectrometers, only two flares affect the daily DDD, but regarding the total DDD over the entire mission, it is negligible $(\sim 0.18 \%)$. One can assume that from June $22^{\text {nd }}, 2008$ to December $31^{\text {st }}, 2012$ only trapped protons in the radiation belts do affect the OSL DDD.

IPSAT-V5.4b-SVN:599

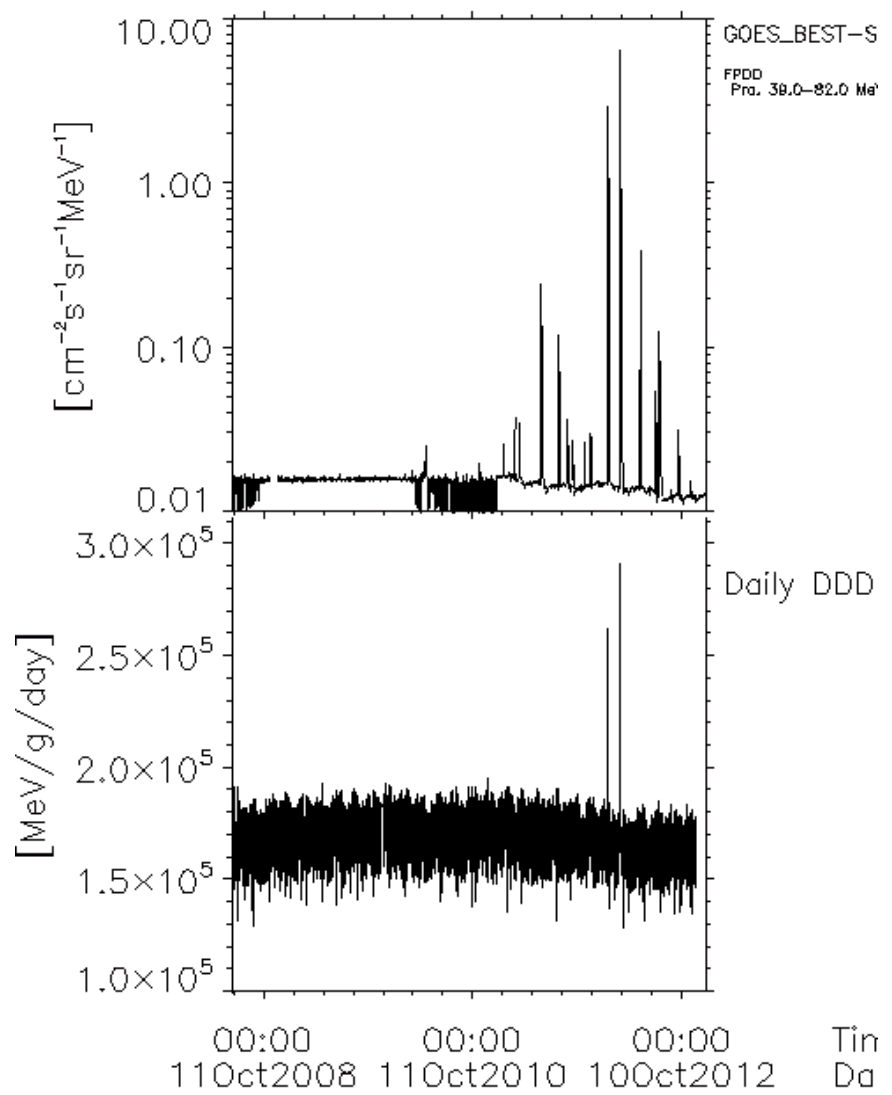

Fig. 10: Measurements of 39-82 MeV solar flare protons by the GOES satellites (top panel) and estimated daily DDD on the OSL from ICARE-NG proton measurements (bottom panel) over time.

B. Calculations using the proton flux from legacy AP8 model or the newly AP9 model

While the AP8 model is well known [1], the AP9 model [4] was only publicly released by September 2012 . There are three specification modes to run AP9 model delineated by the method by which the flux values are determined in each coordinate bin along the orbit: (a) meanthe mean fly-in model captures the mean behavior of the model with no uncertainty added; (b) perturbed mean - the perturbed mean adds the uncertainty in the flux maps due to measurement and gap-filling errors and (c) full Monte-Carlo run contains all of the perturbed mean uncertainty plus an estimate of the dynamic variations due to space weather processes.
The cumulated DDD of the OSL sensor is computed according to (3) where the time integral is running from the beginning of mission to time of interest and $\frac{d \Phi}{d E}(E, t)$ is a 30 days differential omnidirectional spectrum average along JASON-2 spacecraft orbit provided by either AP8 min [1], AP9 perturbed mean, AP9 perturbed median, AP9 perturbed $75^{\text {th }}$ percentile and AP9 perturbed $95^{\text {th }}$ percentile [4]. To compute the averaged spectrum from legacy AP8 min model or the newly AP9 model, the same assumptions were made: JASON-2 spacecraft is flying in the proton model of interest for 30 days long with a time step of 10 seconds along the orbit. The resulting average spectrum is assumed to be constant all over the time period of interest. Note that to get good statistics from the AP9 perturbed model 40 scenarios were considered.

A comparison of cumulated OSL sensor DDD predicted from ICARE-NG spectrometers, AP8 min, AP9 perturbed median, AP9 perturbed $75^{\text {th }}$ percentile and AP9 perturbed $95^{\text {th }}$ percentile is shown in Fig. 11. It turns out that the OSL DDD measures and those predicted from the ICARE-NG spectrometers are within 5\%. Because careful attention was paid to incorporate the full 3D spacecraft geometry in the calculations as well as appropriate ground calibrations of the ICARE-NG instrument all errors in the process are under control. This excellent agreement from two independent ways of accessing the OSL DDD validates the OSL DDD measurements as well as the spectrometers measurements.

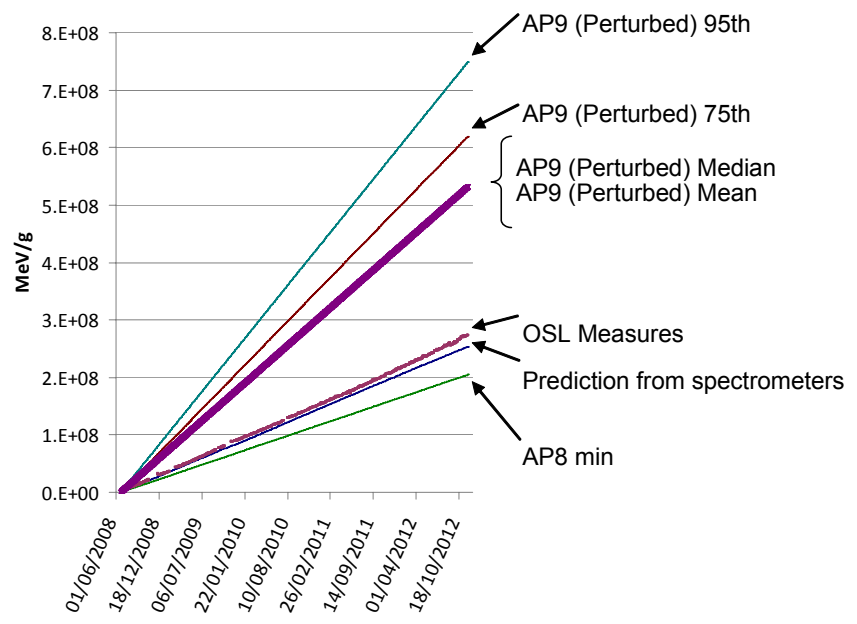

Fig. 11: Comparison of the measurements of the OSL DDD with those derived from the proton measurement with the ICARE-NG spectrometers and AP8 min AP9/Perturbed (40 scenarios).

AP8 min model underestimates the degradation by $24 \%$. Note that both JASON-1 (December 7, 2001 to present) and JASON2 (June 20, 2008 to present) spacecraft were designed with AP8 min plus a 1.2 margin. Both spacecrafts still operate nominally which is consistent with the results presented here from the ionizing radiation point of view. 
AP9 perturbed, mean, median, $75^{\text {th }}$ and $95^{\text {th }}$ percentile models overestimate the degradation respectively by $97.6 \%, 97.6 \%, 130.1 \%$ and $178.3 \%$. According to the OSL response function, it suggests that proton fluxes with energies greater than $40 \mathrm{MeV}$ are overestimated in AP9 while they were underestimated in AP8min.

\section{CONCLUSIONS}

Since June 20, 2008, the ICARE-NG instrument onboard the French JASON-2 spacecraft is providing electron and proton flux as well as DDD continuous measurements (other effect measurements have not been considered in the present study).

The measured DDD on the OSL sensor have been compared to DDD prediction calculated from the spectrometers measurements. The OSL response function could be calculated with high precision as the full spacecraft 3D geometry was known. This has allowed minimizing uncertainties in evaluating the DDD. A difference of 5\% was found between the two approaches to assess the DDD and both the spectrometers and the OSL DDD measurements were thus validated.

ICARE-NG instrument has proven to be an excellent testbed to master the space environment and its effects on electronic parts. Its measurements can be used to validate specification models like the legacy AP8 and the newly available AP9 models. It was found AP8 min underestimates the trapped proton flux by $24 \%$ while AP9 perturbed mean overestimate the trapped proton fluxes by $97.6 \%$.

The same ICARE-NG instrument is flying on-board the Argentinean SAC-D spacecraft since June 10, 2011, a sun synchronous orbit at an altitude of $657 \mathrm{~km}$. Again the 3D spacecraft geometry is well known and a similar analysis will be performed in the future.

\section{REFERENCES}

[1] D.M. Sawyer and J.I. Vette, AP8 trapped proton model environment for solar maximum and minimum, NSSDC/WDC-A-R\&S 76-06, Natl. Space Sci. Data Cent., Greenbelt, MD, 1976.

[2] Daly, E. J., et al., "Problems with Models of the Radiation Belts", in IEEE Trans. Nucl. Sci., 43, 2, 403, 1996.

[3] Rodgers D.J., "Empirical Radiation Belt Models", AGU Geophysical Monograph 1997, 1997.

[4] G.P. Ginet; et al. AE9, AP9 and SPM: new models for specifying the trapped energetic particle and space plasma environment, Space science reviews, in press, 2013.

[5] D. Falguère, D. Boscher, T. Nuns, S. Duzellier, S. Bourdarie, R. Ecoffet, S. Barde, J. Cueto, C. Alonzo, and C. Hoffman, "In-flight observations of the radiation environment and its effects on devices in the SAC-C polar orbit," IEEE Trans. Nucl. Sci., vol. 49, no. 6, pp. 2782-2787, Dec. 2002.

[6] D. Boscher, S. A. Bourdarie, D. Falguère, D. Lazaro, P. Bourdoux, T. Baldran, G. Rolland, E. Lorfèvre, and R. Ecoffet, In Flight Measurements of Radiation Environment on Board the French Satellite JASON-2, IEEE Trans. Nucl. Sci., vol. 58, no. 3, pp. 916-922, June 2011

[7] L. Dusseau, D. Plattard, J.-R. Vaillé, G. Polge, G. Ranchoux, F. Saigné, J. Fesquet, R. Ecoffet, and J. Gasiot, "An integrated sensor using optically stimulated luminescence for in flight dosimetry," IEEE Trans. Nucl. Sci., vol. 47, no. 6, pp. 2412-2416, Dec. 2000.

[8] D. Plattard, G. Ranchoux, L. Dusseau, G. Polge, J.-R. Vaille, J. Gasiot, J. Fesquet, R. Ecoffet, and N. Iborra-Brassart, "Characterization of an integrated sensor using optically stimulate luminescence for in-flight dosimetry," IEEE Trans. Nucl. Sci., vol. 49, no. 6, pp. 1322-1326, Dec. 2002.

[9] J.-R. Vaillé, F. Ravotti, P. Garcia, M. Glaser, S. Matias, K. Idri, J. Boch, E. Lorfèvre, P. J. McNulty, F. Saigné, and L. Dusseau, "Online dosimetry based on optically stimulated luminescence materials," IEEE Trans. Nucl. Sci., vol. 52, no. 6, pp. 2578-2582, Dec. 2005.

[10] P. Garcia, J.-R. Vaillé, D. Benoit, F. Ravotti, L. Artola, B. Sagnes, E. Lorfèvre, F. Bezerra, and L. Dusseau, "Study of the thermal behavior of the OSL integrated sensor response," IEEE Trans. Nucl. Sci., vol. 54, no. 6, pp. 2272-2275, Dec. 2007.

[11] C. Deneau, J.-R. Vaillé, L. Dusseau, J. Mekki, P. Garcia, F. Bezerra, E. Lorfèvre, and R. Ecoffet, First In-Flight Data Analysis of Displacement Damage on the OSL Sensor On-Board CARMEN-2, IEEE Trans. Nucl. Sci., vol. 58, no.3, pp. 939-944, June 2011.

[12] P. Garcia, J.-R. Vaillé, D. Benoit, H. Chabane, G. Berger, K. Idri, J. Boch, B. Sagnes, F. Saigné, E. Lorfèvre, F. Bezerra, and L. Dusseau, "Simultaneous evaluation of TID and displacement damage dose using a single OSL sensor," IEEE Trans. Nucl. Sci., vol. 53, no. 6, pp. 37133717, Dec. 2006.

[13] T. Beutier, E. Delage, M.Wouts, O. Serres, and P. F. Peyrard, "Fastrad new tool for radiation prediction," in Proc. 7th Eur. Conf. Radiation and Its Effects Compon. Syst., pp. 181-183, RADECS 2003.

[14] J. C. Thomas, T. Beutier, P. Pourrouquet, P. F. Peyrard, D. Lavielle, and C. Chatry, "Fastrad: A 3D CAD interface for radiation calculation and shielding," in Proc. 11th Int. Conf. Radiation Shielding, ICRS 2008.

[15] FASTRAD website: [Online]. Available: http://www.fastrad.net/ 